\title{
WELDABILITY OF ALLOY 718, 625 AND VARIANTS
}

\author{
M.C. Maguire and J.R. Michael \\ Sandia National Laboratories \\ P.O. Box 5800 \\ Albuquerque, New Mexico 87185
}

\begin{abstract}
$\underline{\text { Abstract }}$
The fusion zone weldability of a new alloy Inconel $725^{\mathrm{TM}} \dagger$ is presented and compared to Alloys 718, 625 and Carpenter Custom Age 625 Plus $^{\mathrm{TM}^{*}}$. Of these alloys, Inconel 725 and Alloy 718 are most prone to solidification cracking during autogenous gas tungsten arc (GTA) welding as characterized by the Varestraint test. Each alloy typically forms a $\gamma / \mathrm{L}$ aves terminal eutectic solidification product. In addition, other eutectics which form in some alloys include a $\gamma / \mathrm{MC}$ and $\gamma / \mathrm{M}_{6} \mathrm{C}$, depending on composition. Formation of $\delta$ (orthorhombic $\mathrm{Ni}_{3} \mathrm{Nb}$ ) adjacent to Laves and MC carbides in the interdendritic region was peculiar to Inconel 725 welds. Their possible relevance to solidification cracking tendency is discussed in terms of their volume fraction and contribution to solidification temperature range.
\end{abstract}

$\dagger$ Inconel 725 is a registered trademark of Inco Alloys International.

* Carpenter Custom Age 625 Plus is a registered trademark of Carpenter Technologies, Inc.

Superalloys $718,625,706$ and Various Derivatives

Edited by E.A. Loria

The Minerals, Metals \& Materials Society, 1994 


\section{Introduction}

The fabrication and use of Ni-base alloys is often limited by weldability, a property which tends to be strongly dependent on alloy formulation and frequently upon minor alloying additions. Two such alloys, 625 and 718, although different in formulation and application, have become widely used, and ultimately the parents for other alloys that combine the benefits of each. Hardenable by precipitation of the intermetallic $\mathrm{Ni}_{3} \mathrm{Nb}$, Alloy 718 is used for its high strength at moderate temperatures (up to $650^{\circ} \mathrm{C}$ ), corrosion and oxidation resistance, and good creep and fatigue resistance. At room temperature, typical yield and ultimate tensile stresses are 175 and 210 $\mathrm{ksi}$, respectively. One of the primary features of 718 is its improved weldability as compared to $\gamma$ strengthened superalloys with high $\mathrm{Al} / \mathrm{Ti}$ ratios. By introducing $\mathrm{Nb}$ and reducing the $\mathrm{Al} / \mathrm{Ti}$ ratio, the favored precipitate becomes the ordered $\mathrm{BCT} \mathrm{Ni}_{3} \mathrm{Nb}$ phase which forms with slower kinetics than $\mathrm{Ni}_{3}(\mathrm{Al}, \mathrm{Ti})$, the $\gamma^{\prime}$ phase (1). As a result, strain-age or reheat cracking is avoided in subsequent post-weld heat treatment of Alloy 718. One drawback of its weldability is the tendency to fonn solidification cracks and fissuring in the heat-affected zone in high restraint welds $(2,3)$. Addition of $\mathrm{Nb}$ promotes the formation of terminal solidification products, viz., the $\gamma /$ Laves and $\gamma /$ carbide eutectics. The presence of these low melting point constituents favors the retention of a liquid film between advancing dendrites that contributes to solidification cracking.

Alloy 625 is a solid-solution strengthened alloy designed for use in steam and gas turbines. It has also seen applications for marine environments owing to its corrosion resistance. Typical room temperature yield and ultimate tensile stresses in the annealed condition are 60 and $120 \mathrm{ksi}$, respectively. Where higher strengths are necessary 625 can be cold worked, but the useful temperature range is diminished. Although not as prone to solidification cracking during welding as 718 and other nickel-base superalloys, 625 may form similar $\gamma /$ carbide and $\gamma /$ Laves terminal eutectic solidification constituents (4).

Two other alloys of recent development have attempted to fill the gap between Alloys 718 and 625. Each attempts to gain strength by precipitation of $\gamma^{\prime \prime}\left(\mathrm{Ni}_{3} \mathrm{Nb}\right)$ while keeping $\mathrm{Nb}$ at lower levels than is present in 718 to retain the lower solidification cracking tendency of 625 . Carpenter Custom Age 625 Plus $^{\mathrm{TM}}$ and Inconcl $725^{\mathrm{TM}}$ (referrcd to here as 625 Plus and 725) are alloys of similar composition, each with room temperature properties exceeding $120 \mathrm{ksi}$ yield stress and $180 \mathrm{ksi}$ ultimate tensile stress. The solidification and welding metallurgy of 625 Plus has been reported by Cieslak et al. (5). To our knowledge, no data exists on the welding behavior and solidification metallurgy of Inconel 725. This paper will contrast fusion zone weldability data for 725 with 625 Plus, and its parent alloys 718 and 625. Solidification and welding metallurgy are similar for each alloy, but variations in elements such as $\mathrm{Nb}, \mathrm{Si}$ and $\mathrm{Fe}$ produce varying degrees of solidification cracking susceptibility.

\section{Experimental Methods}

The techniques used to investigate the alloys discussed here include differential thermal analysis (DTA), electron microscopy (both scanning and analytical electron microscopy), electron probe microanalysis (EPMA), and Varestraint weldability testing. Conditions for differential thermal analysis and Varestraint testing are given in Ref. 5 .

Analysis of 725 microstructures generated by DTA and welding was performed in a Vacuum Generators HB-501 dedicated Scanning Transmission Electron Microscope equipped with a field emission electron source operated at $100 \mathrm{kV}$ that can produce electron probes which are $1.0 \mathrm{~nm}$ in diameter and contain $1 \mathrm{nA}$ current. The instrument was also equipped with a Link Analytical windowless EDS detector. Quantitative analysis was performed using the Cliff-Lorimer ratio technique and $\mathrm{k}$-factors that were measured from a variety of standards.

\section{Alloy Chemistry}

General alloy chemistry for the 725 alloy discussed here, as well as representative compositions of each of the three alloys based on the Ni-Cr-Mo-Fe-Nb system mentioned previously are shown in Table 1 . The major alloying differences among these materials, and the implication for weldability will be briefly reviewed before specific details are addressed. 
Table I Alloy Compositions

\begin{tabular}{ccccc}
\hline Element & Alloy $718^{1}$ & Alloy $625^{2}$ & 625 Plus $^{2}$ & Inconel 725 \\
& & & & \\
$\mathrm{C}$ & 0.040 & 0.039 & 0.009 & 0.010 \\
$\mathrm{Cr}$ & 18.18 & 22.14 & 21.03 & 20.84 \\
$\mathrm{Al}$ & 0.56 & 0.18 & 0.18 & 0.24 \\
$\mathrm{Ti}$ & 0.95 & 0.26 & 1.31 & 1.64 \\
$\mathrm{Mo}$ & 3.12 & 8.79 & 7.96 & 7.57 \\
$\mathrm{Nb}$ & 5.25 & 3.86 & 3.39 & 3.62 \\
$\mathrm{Fe}$ & 18.10 & 2.54 & 5.18 & 8.72 \\
$\mathrm{Si}$ & 0.21 & 0.10 & 0.03 & 0.92 \\
$\mathrm{Mn}$ & 0.13 & 0.03 & 0.03 & 0.011 \\
$\mathrm{~S}$ & 0.002 & 0.002 & 0.002 & $<0.0006$ \\
$\mathrm{P}$ & 0.014 & 0.005 & 0.007 & 0.011 \\
$\mathrm{~B}$ & 0.002 & 0.0021 & 0.0035 & 0.0048 \\
$\mathrm{Ni}$ & 52.3 & 62.03 & 60.87 & 56.72 \\
\end{tabular}

Carbon levels in 625 Plus and 725 are significantly lower than in either of the parent alloys. Since lower carbon levels tend to reduce the formation of $\gamma / \mathrm{MC}$ and $\gamma / \mathrm{M}_{6} \mathrm{C}$ eutectics, its reduction is aimed at improved weldability. Cieslak (4) has shown that higher carbon levels in 625 increase the tendency for $\gamma / \mathrm{MC}(\mathrm{NbC})$ eutectic formation at the expense of the $\gamma /$ Laves eutectic. The carbide eutectic is the first to form on cooling $(2,4,5)$ and it consumes $\mathrm{Nb}$ prior to formation of the Laves eutectic. Hence, it is not surprising that higher carbon levels would favor a $\gamma /$ carbide eutectic over the $\gamma /$ Laves. In most cases, high Si levels in 625 (>0.40 wt pct) are necessary to promote significant $\gamma / \mathrm{M}_{6} \mathrm{C}$ formation (4); however, the formation of either carbide eutectic is thought to be detrimental to solidification cracking tendency.

Lower Al levels in 625 Plus and 725 relative to 718 are observed to reduce the tendency for $\gamma^{\prime}\left(\mathrm{Ni}_{3} \mathrm{Al}\right)$ formation favoring $\gamma^{\prime \prime}$ precipitation (7). Since the hardening response of $\gamma^{\prime \prime}$ is slower than $\gamma^{\prime}$, strain age cracking is not observed in 718,625 Plus $(1,8)$ or 725 . Alloy 625 contains higher levels of Mo for solid solution strengthening and increased corrosion resistance. Both 625 Plus and 725 contain more Mo than 718 for the same reasons, as well as for its effect on decreasing the solubility of $\mathrm{Nb}$ in the $\gamma$ matrix (8). The Fe content of the alloys varies significantly. The role of iron is not as clear other alloying elements on weldability, but it will be shown that it appears to be a minor player. As mentioned, $\mathrm{Nb}$ forms the basis for precipitation strengthening in 718,625 Plus and 725 . As will be discussed in the next section, it strongly partitions to the interdendritic regions during solidification where it forms the Laves and carbide eutectics as the final stage of solidification. Although $\mathrm{Nb}$ is key to developing the strength of these alloys, it is considered a detriment to weldability.

\section{Solidification, Elemental Partitioning, and Weldability of Alloy 725}

The partition coefficient, $\mathrm{k}$, characterizes the relative thermodynamic tendency of an element to be present in the liquid or the solid during solidification. It is defined as the ratio of the solid composition to the liquid composition at a given temperature within the solidification temperature range. Segregation patterns in weld metals have been analyzed with electron probe microanalysis techniques and reported for 718 (1), 625 (3) and 625 Plus (7). From those analyses, the following segregation patterns have been established. Elements which segregate to interdendritic regions $(\mathrm{k}<1)$ include $\mathrm{Nb}, \mathrm{Mo}, \mathrm{Ti}$, and $\mathrm{Si}$. Those that partition to dendrite cores ( $\mathrm{k}>1$ ) include $\mathrm{Fe}$ and $\mathrm{Cr}$ ( $\mathrm{Ni}$ is considered the solvent and the basis for austenitic solidification).

\footnotetext{
1 From Ref. 2, Alloy 1

2 From Ref 4
} 
Figure 1 shows microprobe traces from 725 . Not surprisingly it is consistent with segregation patterns observed in the other three alloys. One method to determine $\mathrm{k}$ from microprobe data (neglecting kinetic effects such as solid state diffusion, dendrite tip undercooling, and thermal variability in $\mathrm{k}$ ) is to take the ratio of the initial alloy composition to the measured dendrite core composition shown in the microprobe traces of Fig. 1. Table II presents the partition coefficients from 725 , as well as values reported in or calculable by the same method from the literature for 718,625 and 625 Plus. Nb shows the strongest tendency to partition to the interdendritic region. Other elements such as Mo, Ti, and Si show similar but weaker partitioning behavior. The last liquid to solidify is enriched in these elements hence the formation of Laves, carbide, and other intermetallic compounds.

Table II Measured Partition Coefficients*

\begin{tabular}{cccccccc}
\hline & & \multicolumn{9}{c}{ Element } \\
Alloy & $\mathrm{Nb}$ & $\mathrm{Mo}$ & $\mathrm{Cr}$ & $\mathrm{Fe}$ & $\mathrm{Ti}$ & $\mathrm{Si}$ \\
\hline 7181 & 0.50 & 0.83 & 1.03 & 1.1 & 0.71 & 0.82 \\
$625^{2}$ & 0.52 & 0.80 & 1.0 & 1.1 & NA & 0.57 \\
625 Plus $^{3}$ & 0.53 & 0.89 & 1.0 & 1.0 & 0.57 & NA \\
725 & 0.55 & 0.79 & 0.99 & 1.1 & 0.66 & NA \\
\hline
\end{tabular}

Terminal solidification of alloy 725 is characterized by the formation of 2 minor products, shown in the DTA thermogram of Fig. 2. Cooling and heating rates were $0.33^{\circ} \mathrm{C} / \mathrm{s}$ with a peak temperature of $1550^{\circ} \mathrm{C}$. Reaction temperatures are taken as described in Ref 4 . The thermogram shows that on heating the homogeneous alloy encounters the solidus at $1231^{\circ} \mathrm{C}$ and the liquidus at $1335^{\circ} \mathrm{C}$. Upon cooling, the austenitic matrix supercooled in the alumina crucible to $1324^{\circ} \mathrm{C}$ before solidification started, and two minor reactions took place at $1143^{\circ} \mathrm{C}$ and $1118^{\circ} \mathrm{C}$. Each of these corresponds to the $\gamma / \mathrm{MC}$ and $\gamma /$ Laves eutectic, respectively. Other investigators have shown that the carbide eutectic forms first on cooling in each of these alloys $(2,4,5)$. This data, in conjunction with the microscopy presented below indicate that 725 has the same solidification sequence. Figure 3 shows a transmission electron micrograph of a DTA sample. Shown is the formation of a blocky type of Laves, smaller MC carbides along the periphery of the Laves, lens shaped precipitates of $\gamma^{\prime \prime}$, and growth of $\delta$ needles from the Laves and carbide interfaces. Formation of the $\gamma^{\prime \prime}$ and $\delta$ were the result of solid state precipitation reactions similar to those of Alloy 718. The morphology of the Laves was blocky, with none of the lamellar structure characteristic of 718 .

Figure 4 illustrates the appearance of a typical GTA weld in 725. In these backscattered electron images, the dendritic structure and lighter appearing interdendritic constituents, indicative of higher atomic number components of the phases present are evident. Analytical electron microscope (AEM) examination identified the interdendritic material as predominantly Laves phase, with small amounts of MC carbide and $\delta$ phase. The amount and size of these phases were reduced relative to the DTA sample shown in Fig. 3. The occurrence of $\delta$ was also reduced, but still evident, as shown in the TEM micrograph of Fig. 4(b). The appearance of $\delta$ at such relatively rapid cooling rates, approx. $500^{\circ} \mathrm{C} / \mathrm{s}(2)$, is unexpected. It was not observed in similar studies of 718, 625 or 625 Plus $(2,4,5)$. Also shown in Fig. 4 is the mottled appearance

\footnotetext{
* Values vary in accuracy based on measurement technique. All are withing 10 pct relative

${ }^{1} \mathrm{k}$ for $\mathrm{Nb}$ reported in Ref. 1 (4 heat avg); remainder are calculated from data in reference.

2 From Ref. 2.

3 From Ref. 7.
} 

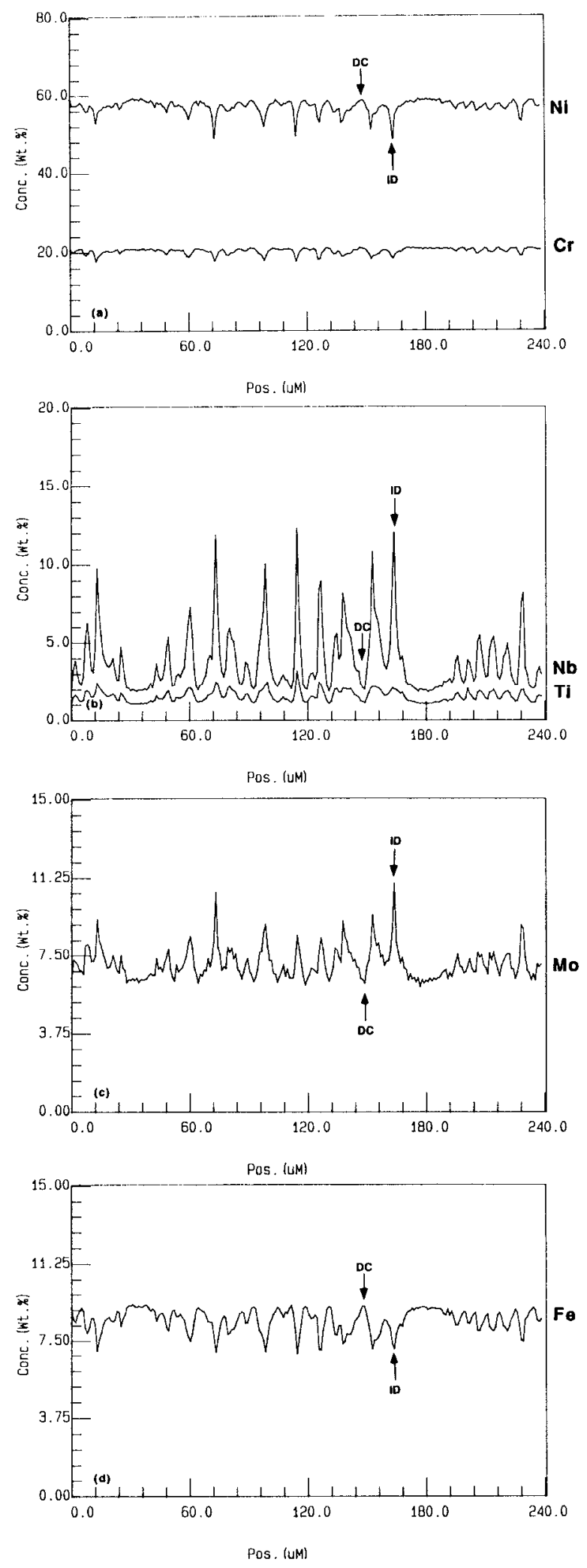

Figure 1 - Microprobe trace across weld of Inconel 725. Arrows indicate dendrite core (DC) and interdendritic (ID) regions. 


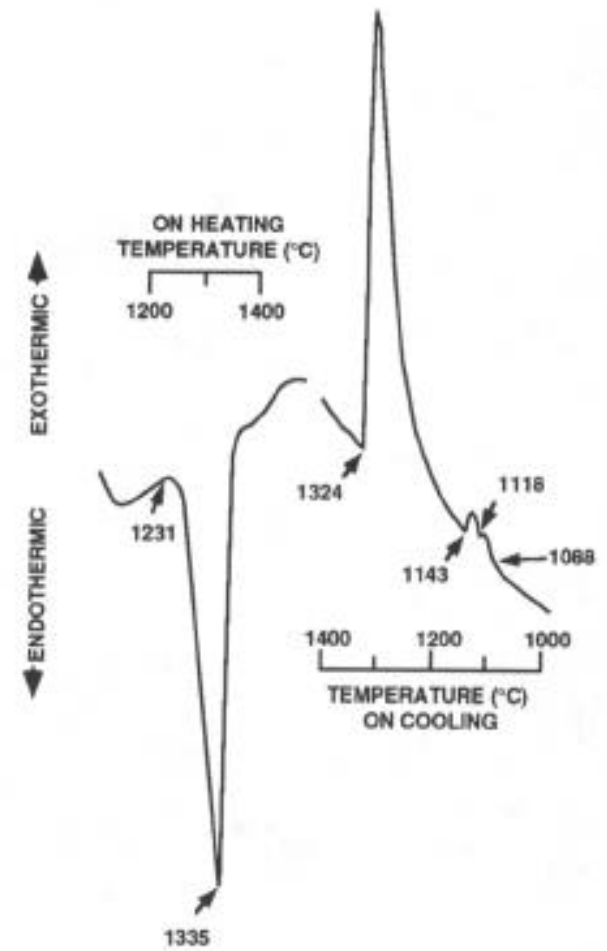

Figure 2 - DTA thermogram of Inconel 725. Heating and cooling was $0.33^{\circ} \mathrm{C} / \mathrm{s}$, with a peak temperature of $1550^{\circ} \mathrm{C}$

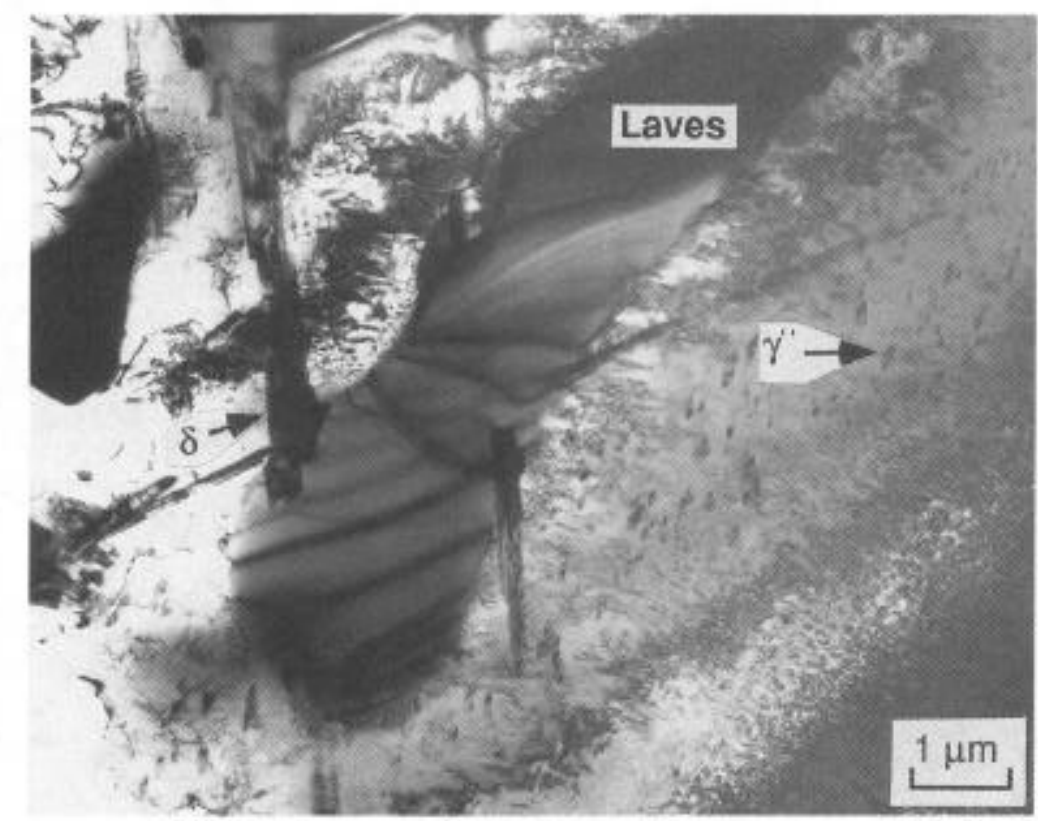

Figure 3 - Bright field TEM micrograph of the DTA sample microstructure. Laves, $\delta$, and $\gamma^{\prime \prime}$ are indicated by arrows. 

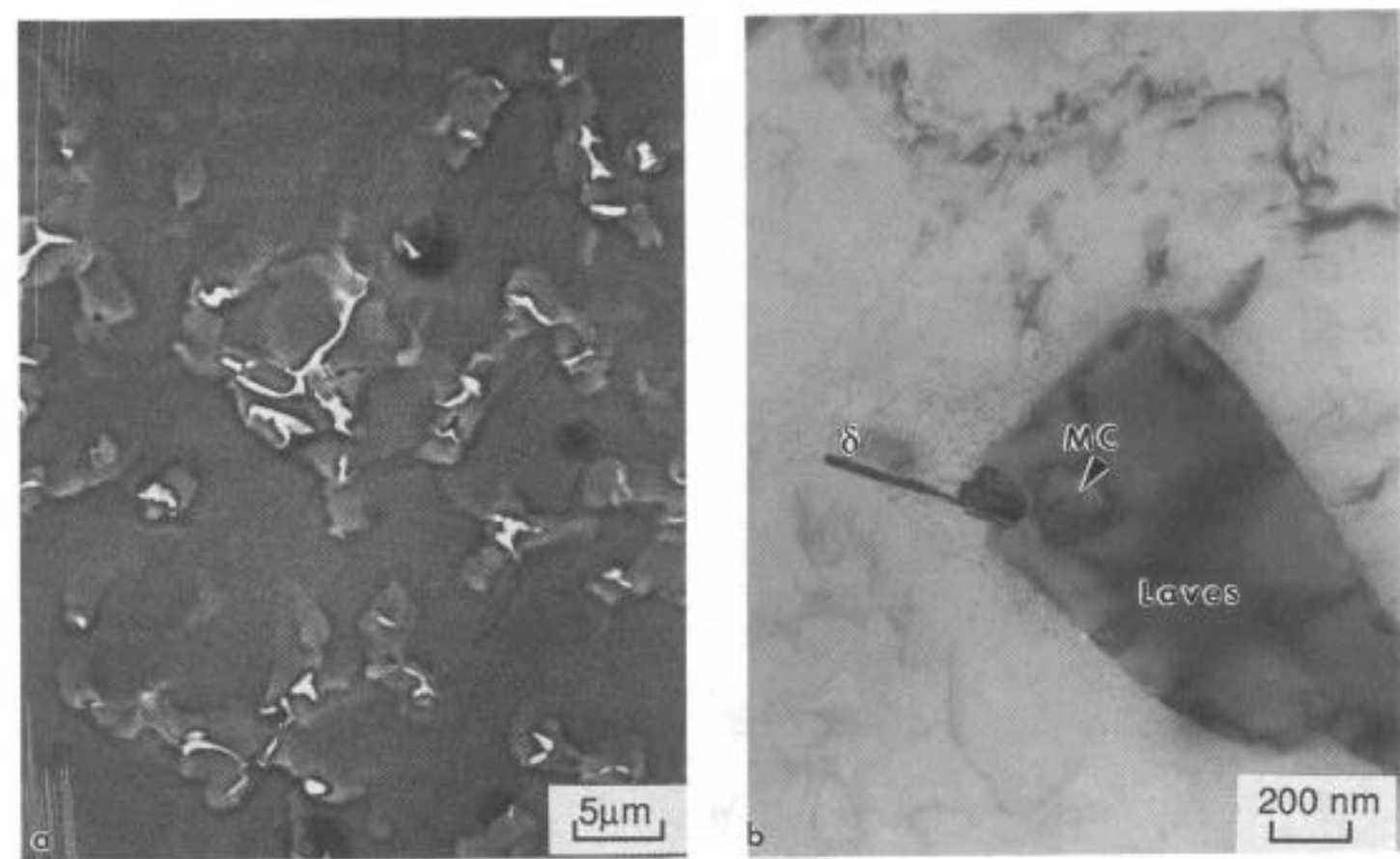

Figure 4 - GTA weld microstructure as seen in : (a) backscattered SEM, (b) TEM showing Laves, and $\delta$ precipitate. Mottled structure around Laves is indicative of $\gamma^{\prime \prime}$ precipitation.

Table III Phase Compositions from AEM in Inconel 725 (wt. pct)

\begin{tabular}{crrrrrr}
\hline Phase & $\mathrm{Ni}$ & $\mathrm{Fe}$ & $\mathrm{Cr}$ & $\mathrm{Ti}$ & $\mathrm{Nb}$ & Mo \\
\hline & & & & & & \\
\hline DTA Laves & 40.0 & 6.8 & 19.6 & 1.0 & 16.2 & 16.5 \\
DTA Weld $\delta$ & 75.0 & 1.6 & 3.0 & 4.6 & 13.8 & 2.2 \\
DTA $\gamma^{\prime \prime}$ & 75.5 & 1.8 & 2.8 & 5.6 & 12.6 & 1.8 \\
$\quad$ Weld Laves & 47.5 & 7.4 & 20.2 & 1.3 & 11.9 & 11.8 \\
Weld Carbide* (small cuboidal) & 15.9 & 2.1 & 10.7 & 16.8 & 43.2 & 11.5 \\
Weld Carbide* (large blocky) & 4.4 & 0.7 & 1.2 & 34.4 & 30.9 & 28.4 \\
& & & & & & \\
Values are accurate to \pm 5 pct relative & & & & & & \\
* Metal content only & & & & & & \\
\hline
\end{tabular}

of the matrix adjacent to the Laves phase resulting from the precipitation of $\gamma^{\prime}$. Table III shows the summary compositions of the phases found in Inconel 725 .

The hot cracking susceptibility of Inconel 725 was characterized by the Varestraint test, results of which are shown in Fig. 5. This figure shows the maximum crack length averaged over several test bars. Also included in the figure are data for the other three alloys in Table I. As is evident from Fig. 5, 625 and 625 Plus are least sensitive to hot cracking as characterized by their lower crack length. Alloy 725 appears to be more sensitive to hot cracking than 718 . As stated, in highly restrained joints, 718 is known to be susceptible to hot cracking. The data in Fig 5 . predict that 725 will be even more prone to this same problem. 


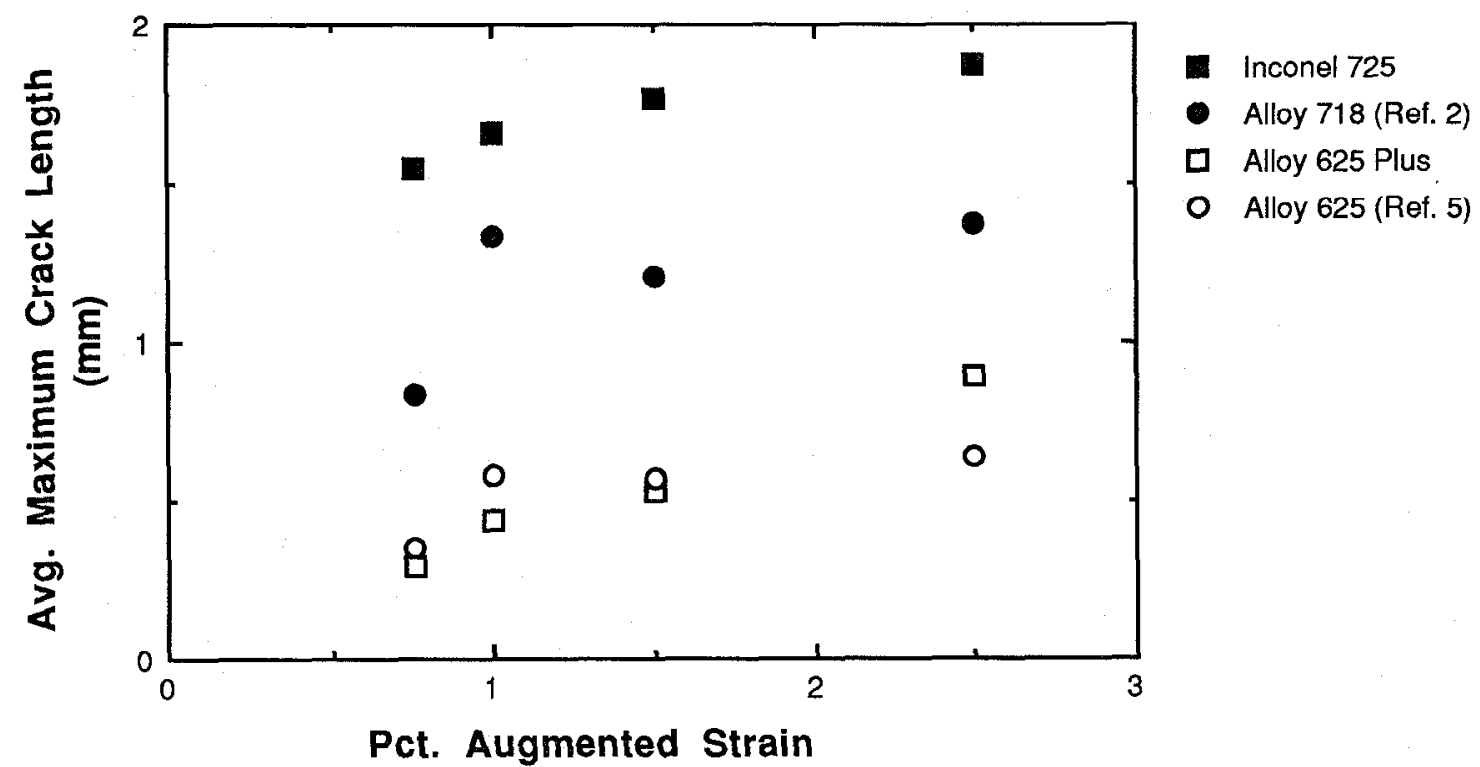

Figure 5 - Varestraint cracking response in terms of average maximum crack length for the alloys of interest.

\section{General Weldability Considerations of Alloy 718,625 and Variants}

With the preceding data as reference, welding issues common to these alloys will now be discussed. Of specific interest are the influence of segregation phenomena, and the resulting interdendritic liquid that appears to influence hot cracking resistance.

The role of segregation phenomena is extremely important when considering weldability and solidification of weldments. The solidifying dendrites are enriched or depleted in solute depending on the distribution coefficient, $\mathrm{k}$, for each element. This enrichment is responsible for the formation of the $\gamma /$ Laves and $\gamma / \mathrm{MC}$ eutectics which form at the end of solidification. As stated, Mo, Nb, Ti and Si partition to interdendritic regions and are generally found at greater concentrations in the Laves phase than in either the bulk composition or the eutectic $\gamma$ phase. Figure 6 shows the Laves composition found in welds for each of the four alloys shown in Table I. Since each weld was made with nearly identical parameters, solidification conditions are considered constant. The $\mathrm{Ni}$ and $\mathrm{Cr}$ content of the Laves are fairly uniform, with the lowest $\mathrm{Cr}$ level indicative of the alloy with the lowest bulk $\mathrm{Cr}$ level, Alloy 718. Other elements such as $\mathrm{Fe}$, $\mathrm{Nb}$, and Mo also appear to show a relationship to bulk alloy composition. For example, bulk Mo content in 718 is the lowest of the four alloys, and the 718 Laves phase has the lowest Mo content. Conversely, the $\mathrm{Nb}$ level is highest in 718 and is present in greater abundance in the Laves for that alloy.

The anomalous behavior of $\mathrm{Ti}$ has been discussed by other investigators $(2,3)$. Although Ti partitions to interdendritic regions, it does not appear to partition to the eutectic Laves. This seems counter-intuitive since Ti forms a prototypical Laves phase with $\mathrm{Fe}$ as $\mathrm{Fe}_{2} \mathrm{Ti}$, although there is no Ni2 Ti phase in the Ni-Ti binary. Examination of carbide compositions indicate that $\mathrm{Ti}$ plays a much larger role in the (Nb,Ti)C eutectic than it does in the $\gamma /$ Laves eutectic.

The Fe level in the Laves is also lower than the bulk composition indicating that although it may play a role in promoting Laves formation by destabilizing the $\gamma$ matrix, it does not seem to strongly influence Laves formation in these alloys. In fact, it does not partition to the interdendritic region. Figure 7 compares the relative enrichment of the Laves phase - defined as the ratio of the Laves composition to the bulk alloy composition - for each alloy. Differences in each alloy are less apparent. Once again, strong enrichment of the Laves phase in $\mathrm{Nb}$ and $\mathrm{Mo}$ is 
evident. Studies of 625 and $718(2,4)$ also show strong Si enrichment of Laves.

Carbide formation in 718, 625, and 625 Plus occurs first during the solidification sequence as shown by other investigators. The same sequence of formation in Inconel 725 produces a relatively larger amount of Laves relative to the carbide, shown in Fig. 4. Although microscopy indicated that the fraction of carbide relative to Laves was small, both eutectics show simila peak intensities on the DTA thermogram of Fig. 2. However, the peak height is also dependent on the enthalpy of formation for each phase. Note also in Table III that two types of MC carbide morphology were observed in Inconel 725 welds, small cuboidal carbides a few microns in diameter, and larger blocky carbides tens of microns in diameter. Significant compositional differences exist between each, leading to the conclusion that their temperature of formation was significantly different. It is possible for $\mathrm{MC}$ carbides to precipitate in the solid state. Data for 718 (8) indicates that it can form with faster kinetics that $\delta$, which is seen in 725 weldments. It is possible that the smaller carbides formed in the solid state in the solute rich interdendritic regions.

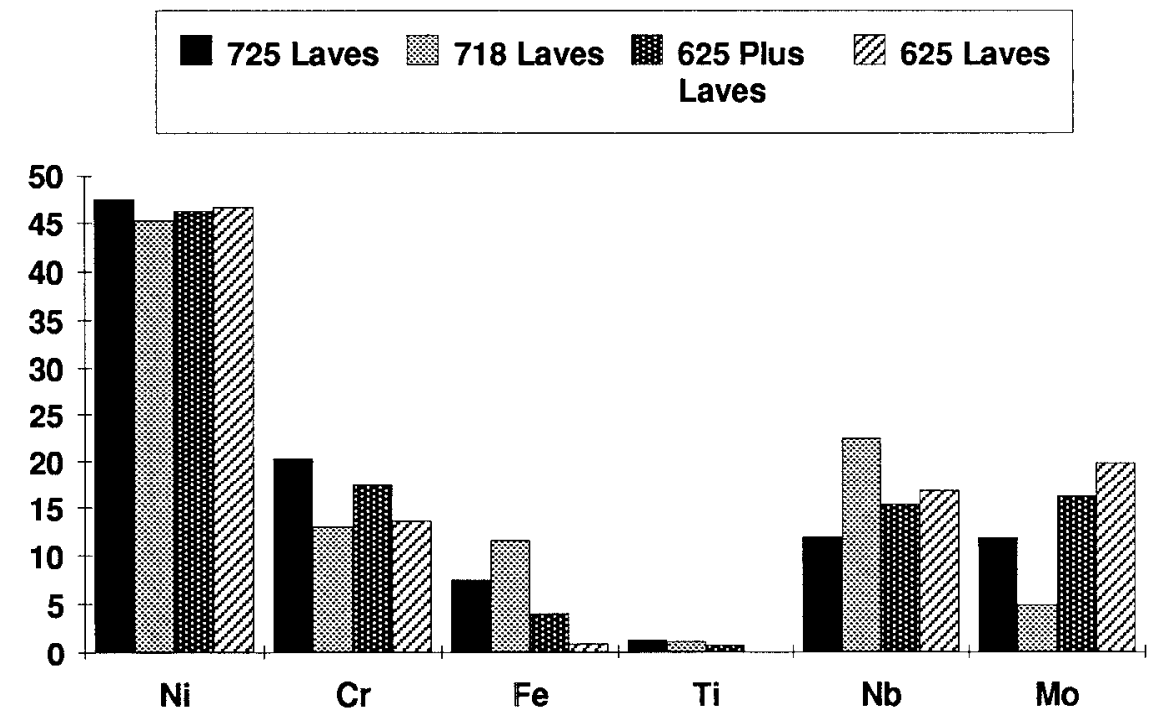

Figure 6 - Laves composition in weldments for each of the alloys of interest (wt. pct).

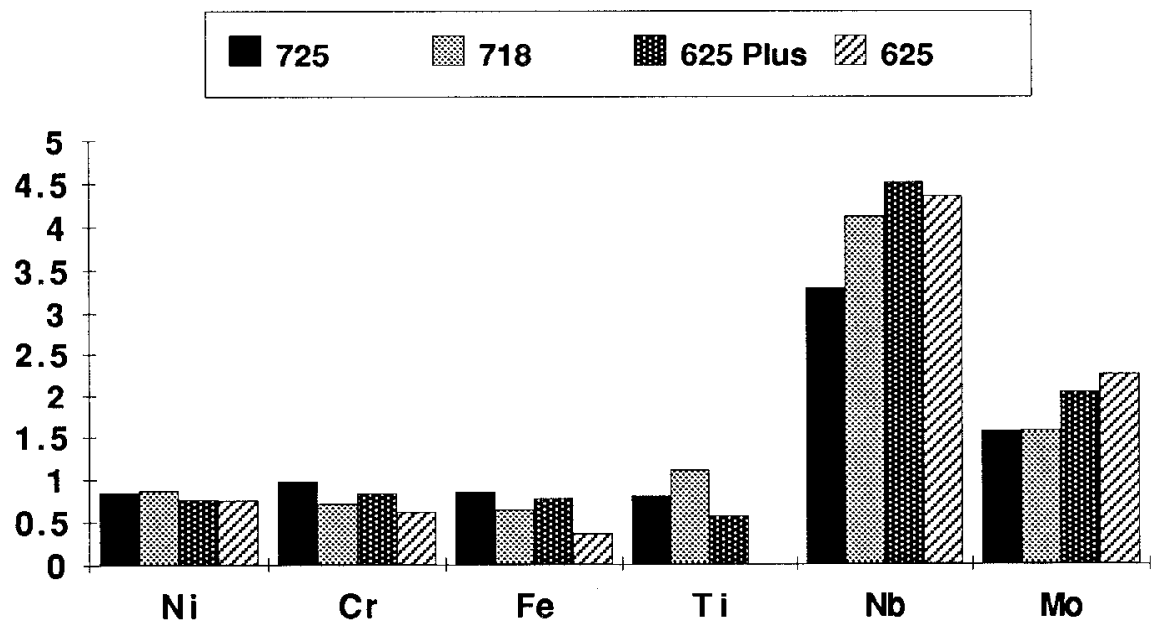

Figure 7 - Relative enrichment of Laves phase relative to the bulk composition for the alloys of interest (wt. pct). 
Although the previous discussion of solute scgregation indicates that many clements contribute to Laves and carbide eutectic formation only the Laves will be discussed here in terms of its effect on weldability and solidification cracking since it is in relative abundance and is the last to solidify. Furthermore, Eiselstein (9) and Knorovsky (2) have shown that the volume fraction of eutectic that forms during solidification can be accurately predicted by only considering the partitioning of $\mathrm{Nb}$ for 718 . Based on a Scheil analysis (10), neglecting diffusion in the solid, dendrite curvature effects, secondary branching, and assuming thermodynamic equilibrium at the interface, the fraction of eutectic can be determined as:

$$
f_{e}=\left(\frac{C_{e}}{k C_{0}}\right)^{\frac{1}{k-1}}
$$

where $\mathrm{C}_{\mathrm{e}}$ is the composition of the proeutectic phase at the eutectic temperature, and $\mathrm{f}_{\mathrm{e}}$ is the weight fraction eutectic. For 718 (2), $\mathrm{C}_{\mathrm{e}}$ was measured to be $9.3 \mathrm{wt}$. pct, and using the above equation, the fraction eutectic for 718 was calculated to be 6.6 to 9.0 pct for alloys of that study. Corrections to account for volume pct proved inconsequential. These levels of eutectic correlated well with the observed structures of welds. If a similar $C_{e}$ is assumed for Inconel 725, and $C_{0}$ and $\mathrm{k}$ are taken from the EPMA data, then an $\mathrm{f}_{\mathrm{e}}$ of 3.3 pet is calculated. Quantitative metallography of SEM micrographs from polished welds yields a value of $2.9 \mathrm{pct}$ for the volume fraction of Laves eutectic. Although the agreement seems good, the morphology of the Laves phase in 725 is blocky in contrast to the distinctly lamellar structure in $718(2,4)$, which makes identification of eutectic volume fraction rather than the Laves fraction difficult for 725 . Despite this difficulty in interpretation, Inconel 725 clearly contains significantly less Laves than 718.

Solidification cracking theory holds that the liquid film present during solidification is responsible for the formation of cracks. Neglecting eutectic healing for the moment, it is then reasonable to assume that if more of this liquid is present, the worse the cracking tendency should be. This was the argument offered in a study of 625 Plus when comparing its improved weldability in contrast to 718 (5). However, the same argument does not hold here for Inconel 725. Its volume fraction of eutectic Laves is similar to 625 Plus, but its solidification cracking tendency is much worse.

Another contributory cause to solidification cracking is a wide solidification temperature range. By considering this temperature range to be the difference between the liquidus on heating and the temperature corresponding to the last constituent to solidify on cooling from DTA thermograms (the true solidus for a material solidifying with segregation), these values are 247 , 283,187 and $266^{\circ} \mathrm{C}$ for Alloys $725,718,625$, and 625 Plus, respectively. These data predict that Alloys 725, 718 and 625 Plus should all behave similary in Fig. 5. This is not observed. These data also show that 625 and 625 Plus have distinctly different solidification temperature ranges, but welds have almost identical hot cracking behavior. Inconel 725 has the lowest cracking resistance, yet it has a smaller solidification temperature range than 625 Plus. $\Lambda$ lthough these alloys differ in composition, they all solidified under similar conditions in the DTA test, form nearly identical phases, yet show widely varying solidification cracking resistance. No consistent correlation can be made for the alloys.

Since the cracks form as the terminal eutectics solidifiy, the temperature range of interest could also be the range over which the terminal solidification products form, not the temperature range identified as starting at the liquidus. This narrower range corresponds to 55, 191, 75, 36 for $725,718,625$ and 625 Plus, respectively. These data predict that 718 would exhibit the worst hot cracking behavior, followed by 625 and 725 . Clearly this is not realistic either.

Although a consistent explanation for the solidification cracking resistance does not appear to be readily available for these alloys, several points of interest should be mentioned. First, observations by other researchers concerning the role of $\mathrm{Nb}$ in promoting the formation of Laves being primarily responsible for its abundance in welds has been corroborated. Sccondly, 
comparison of Inconel 725 to 625 Plus shows that the only major differences in composition occur in the $\mathrm{Fe}$ and $\mathrm{Si}$ contents. The behavior of $\mathrm{Fe}$ was discussed above and it was found that it does not partition to interdendritic regions, and it is not preferentially distributed in the Laves or carbide phases. Hence, it is unlikely that Fe strongly influences solidification cracking in these alloys. The remaining clement, Si was not analyzed in the present experiments for 725 , but it is known to strongly partition to interdendritic regions and promote Laves formation $(2,4)$. However, there was no significant increase in Laves abundance in 725 relative to 625 Plus, but the solidification cracking response was markedly different. The solidification temperature range for these alloys is also quite similar which leads one to conclude that none of the traditional phenomenology for describing solidification cracking completely describes these alloys. Solidification cracking theory also involves surface tension and viscosity, but determining such values is experimentally difficult. However, it appears that there is some other determining factor for hot cracking that has not been accounted for in comparing the behavior of these alloys.

\section{Summary}

The fusion zone weldability as determined by Varestraint testing in terms of solidification behavior for a new alloy, Inconel 725, has been reviewed and compared to its closest relatives in the superalloy family. DTA and AEM analyses indicate that Inconel 725 terminates solidification with the formation of two eutectics: first a $\gamma / \mathrm{MC}$ then a more abundant $\gamma /$ Laves eutectic. Welds also show formation of $\delta$ at $\gamma /$ Laves interfaces. Solidification phenomena of each of the alloys presented are similar, yet the solidification cracking resistance does not follow intuitive trends developed from studies of the other alloys based on the relative volume fraction or solidification temperature range. A consistent understanding of solidification cracking tendency has yct to be developed.

\section{Acknowledgments}

The authors wish to thank N. Simmons for technical assistance, F. Greulich and A. Kilgo for metallographic assistance, P. Hlava for the microprobe work, T. Tribble for TEM specimen preparation, and G. Knorovsky for review of the manuscript. This work was performed at Sandia National Laboratories supported by the U.S. Department of Energy under contract number ACO3-76DP00789.

\section{References}

1. D.F. Paulonis, J.M. Oblak, and D.S. Duvall, "Precipitation in Nickel-Base Alloy 718," Trans. ASM, 62 (1969), 611-622.

2. G.A. Knorovsky et al., "INCONEL 718: A Solidification Diagram," Metallurgical Transactions A, 20A (1989), 2149-2158.

3. "The Solidification Metallurgy of Alloy 718 and Other Nb-Containing Superalloys," Superalloy 718-Metallurgy and Applications, ed. E.A. Loria (Warrendale, PA: The Metallurgical Society, 1989), 59-67.

4. M.J. Cieslak et al., "A Melting and Solidification Study of Alloy 625," Metallurgical Transactions A, 19A (1988), 2319-2331.

5. M.J. Cieslak, T. J. Headley, and R.B. Frank, "The Welding Metallurgy of Custom Age 625 PLUS Alloy," Welding Journal, no. 12 (1989), 473s-482s.

6. M.J. Cieslak et al., "A Comparison of the Solidification Behavior of INCOLOY 909 and INCONEL 718," Metallurgical Transactions A, 21A, (1990), 479-488.

7. "A Weldability Study of Haynes Alloy 242", Weldability of Materials, ed. R.A. Patterson and K.W. Mahin (Materials Park, OH: ASM International, 1990), 167-173. 
8."Nickel-Iron Alloys," Superalloys II. ed. C.T. Sims, N.S. Stoloff, and W.C. Hagel. (New York, NY: John Wiley and Sons, 1987), 165-188.

9. H.L. Eiselstein, Advances in the Technology of Stainless Steels: (Philadelphia, PA: ASTM STP 369,1965$), 62-79$.

10. E. Scheil, "Bemerkungen sur Schichtkristallbildung," Z. Metallkunde, 34 (1942), 7-72. 